\title{
Alpha enhancement in global equity markets with ESG overlay on factor-based investment strategies
}

\author{
Subhransu S. Mohanty ${ }^{1}$ (D) Odette Mohanty ${ }^{2} \cdot$ Mike Ivanof $^{3}$
}

Accepted: 24 May 2021 / Published online: 8 June 2021

(c) The Author(s), under exclusive licence to Springer Nature Limited 2021

\begin{abstract}
Studies show that companies with a strong Environment, Social and Governance (ESG) profile are more competitive than their peers, as they use resources, human capital and innovation more efficiently. High ESG-rated companies have lower exposure to systematic risk factors and low expected cost of capital, leading to higher valuations in a DCF model framework. They are typically more transparent, particularly with respect to their risk exposures, risk management and governance standards and have better long-term vision. The paper finds that higher Alpha can be harvested by restricting investment exposure to the ESG theme combined with various style characteristics, as they display low systematic and idiosyncratic tail risks. It shows that an ESG overlay on such factor-based strategies, particularly on 'multifactor', 'value' and 'low volatility' in that order, reduces both systematic and idiosyncratic risks further. ESG overlay on 'quality' factor provides the highest return among ESG target indices, however, the underlying 'quality' factor provides even higher excess return. These findings can provide some insight on return enhancement to investors investing in the global equity markets.
\end{abstract}

Keywords Global equity markets · Alpha enhancement · Market risk · Idiosyncratic tail risk $\cdot$ Factor risk $\cdot$ Environment $\cdot$ Social and Governance (ESG)

JEL classification $\mathrm{G} 11 \cdot \mathrm{G} 12 \cdot \mathrm{G} 14 \cdot \mathrm{G} 15 \cdot \mathrm{G} 17$

Subhransu S. Mohanty

drssmohanty@gmail.com; drssmohanty@smartinternationalholdings.org

Odette Mohanty

odettefcsi@gmail.com

Mike Ivanof

mike.ivanof@ufv.ca

1 SMART International Holdings, Inc., Wilmington, DE, USA

2 Bank Dhofar SAOG, Muscat, Oman

3 University of the Fraser Valley, Abbotsford, Canada 


\section{Introduction}

In a market, the investment behavior of investors is mainly guided by expected return and variance of return on their investments. Both these factors being futureoriented and uncertain, investors assume a certain amount of risk. According to Hicks (1939), expected returns from investments include an allowance for risk. This risk varies from security to security and if market imperfection exists, an investor would like to maximize future returns by selecting the most robust portfolio of securities which are diversifiable based on the variation in risks, rather than holding a security where risk is non-diversifiable. This led to the Markowitz formulation of optimal portfolio construction which postulates that the expected return of a portfolio is a function of the returns of constituent securities and the covariance of such returns. Hence, an optimal market portfolio has diversifiable assets eliminating away the idiosyncratic risk associated with each of the constituents and has the systematic risk associated with the entire market. Based on the Markowitz theory and within the Capital Asset Pricing Model (CAPM) framework, the beta of a company measures its systematic risk exposure (i.e., lower beta means less systematic risk) and hence investors' expected return from it will be lower than the expected return from the market. In contrast to this, from the Discounted Cash Model (DCF) perspective, a lower expected/required rate of return represents a lower cost of capital and hence can generate higher discounted cash flows or expected return on investment, than a company which has a higher cost of capital (cf. Ruefli et al. 1999). This fact is further reinforced by a review of a number of studies conducted, which unanimously established that companies with high ESG ratings have an ex-ante lower cost of capital both for equity and debt (Fulton et al. 2012). Secondly, if a company has lower beta or lower systematic risk, then there could be idiosyncratic firm-specific characteristics associated with that company, which bring down its systematic risk exposure. A large pool of literature (more than 2100) also indicated a high correlation between ESG factor implementation and corporate financial performance at firm level (Friede et al. 2015). This point of view is supported by the early work of Ross (1976) who developed the Arbitrage Pricing Theory, observing that excess return cannot be achieved with the market factor alone, but with multiple factors. Additionally, empirical work of Black, Jensen, and Scholes demonstrated that "low beta" assets earn a higher return on an average and "high beta" assets earn a lower return on an average. Continuing academic and non-academic empirical research shows that there are many anomalies to counter the risk-return efficiency of assets and their markets. Merton (1973) says that upto four unspecified state variables lead to risk premiums that are not captured by the market factor. Since these unspecified state variables haven't been identified and measured, later empirical studies mostly deal with excess return (alpha) generation through factor portfolios providing different combinations of exposures to the unknown state variables within the relevant multifactor efficient set along with the market portfolio and the risk-free asset". Notable among them, are the Fama-French 3-factor model, the Carhart 4-factor model, the Fama-French 5-factor model (Fama and French 2015) and the Asness and Frazini's 6-factor model. In general, small companies are considered more risky than the big 
ones, as they are less liquid, even though some of them may be highly profitable, stable and growing at a faster rate. Similarly, high book-to-market, though technically pointing to the possibility of delivering better returns in future, could instead be due to higher retention policy, not having enough opportunities to grow further and so on. The two factors, such as Robust-minus-Weak (RMW, the profitability premium) and Conservative-minus-Aggressive (CMA, the investment premium) provide another dimension to stock characteristics, i.e., more profitable companies are expected to have a higher valuation compared to the less profitable ones and high book-equity growth means a lower valuation growth. The QMJ (quality minus junk) factor or quality premium adds a few more parameters to profitability, such as growth (higher price for stocks with growing profits), safety (both return-based measure of safety, i.e. volatility risk relative to market risk, and fundamental-based measures such as stocks with low leverage, low volatility of profitability, and low credit risk) and payout ratio (higher payout means less of management agency problems, Jensen 1986). The momentum factor always increases market risk and vice versa. Similarly, the BAB (betting against beta) factor explains liquidity preference (Harvey et al. 2007), liquidity funding risk (Acharya and Pedersen 2005) and portfolio constraints in a generic market setting. Accordingly, low beta stocks have high expected returns, and netting of low beta stocks against high beta stocks takes away some amount of market risk. Additionally, the low risk anomaly has been further substantiated with more findings on liquidity preference, liquidity funding risk and portfolio constraints in a generic market setting, which shows that low beta stocks have high expected returns. Asness, Frazzini and Pedersen, through a number of studies, discovered that leverage adds to risk (Asness et al. 2012) and hence, low risk investments have higher expected return (Betting against Beta, Frazzini and Pedersen 2014) and quality stocks have higher return than junk stock (Quality minus Junk, Asness et al. 2017). Their work was inspired by earlier findings on: positive association of low beta with high alpha (Black et al. 1972; Frazzini and Pedersen 2014); dividend growth as the market's quality parameter (Campbell and Shiller 1988; Vuolteenaho 2002; Fama and French 2008); impact of cash flow betas' on price levels (Cohen et al. 2009); firms with low leverage have high alpha (George and Hwang 2010; Penman et al. 2007); firms with high credit risk tend to underperform (Altman 1968; Ohlson 1980; Campbell et al. 2008). The low beta and quality factors provide a further dimension to risk-based explanations of returns.

The decomposition of factor Alphas helps in measuring and monitoring risk exposure and performance attribution of investment portfolios in a more granular and accurate fashion. All these models are highly intuitive and provide additional cross-sectional risk-return dimensions to the market risk based on size, value, momentum, profitability, investment, quality and low beta effects.

In a previous study on market factors, we find significant variations in explaining sources of risk across 22 developed and 21emerging markets. Though the capital asset pricing model (CAPM) provides an excellent risk-return framework and the market beta may reflect the risk associated with risky assets, we find that lower market risk results in higher excess return in 19 out of the 22 developed markets and in 17 out of the 21 emerging markets, which is a major anomaly (Mohanty 2018). 


\section{Why (environment, social and governance) ESG tilt matters}

Until the financial crisis of 2008, the primary focus of Governments globally was on strengthening the regulatory framework for businesses, so as to contain the economic recession. The reforms that followed, saw the emergence of the sustainability concept which was widely acclaimed to be vital in ensuring the economic stability and social well-being of future generations. Alongside this, is the need to recognize the challenge of competition faced due to globalization and crossborder business interests. Globalization, the growing world population and the rise of emerging economies have resulted in increased competition over natural resources on a global scale, higher prices and a debilitating pressure on the environment. In the face of these challenges, companies are already looking for ways to increase the efficiency of their resource use. Thus, according to the European Union, competitiveness and sustainability are mutually reinforcing concepts. The United Nations International Development Organization has come out with the Millennium Development Goals and states that inclusive and sustainable industrial development will be a key driver for the successful integration of the economic, social and environmental dimensions of sustainable development. Business models for sustainable development aim to deliver economic, social and environmental benefits - the three pillars of sustainable development (also known as the Triple Top Line, coined by John 1964 cited by McDonough and Braungart 2002). During the past decade, environmental practices and social policies affecting society and communities have become tightly integrated with corporate governance. These related issues, which are the responsibility of the Board of Directors, are referred to collectively as "ESG." Many ESG issues are defined in terms of enhanced business risk. Many are categorized as "non-financial" or "longterm" issues, in specific contrast to the quarterly earnings and short-term financial metrics that have been the principal concern of both investors and companies leading up to the global financial crisis of 2008. As a result of the crisis, business and investor groups have been looking for ways to break the short-term cycle, reinforce corporate governance and develop performance metrics that reflect ESG and non-financial goals. The International Financial Corporation (IFC) espouses that in a time of resource scarcities and rising social pressures, businesses face a growing need for a stronger approach to ESG issues.

The United Nations Principles of Responsible Investing state that "ESG issues can affect the performance of investment portfolios to varying degrees across companies, sectors, regions, asset classes and through time". The Chartered Financial Analysts Institute (CFA Institute) says that "every investment analyst should know about the risks and opportunities of ESG issues as the ESG investing ethos embodies our efforts to promote a fiduciary culture and a more sustainable form of capitalism through our Future of Finance initiative. There is a global effort to shape a more trustworthy, forward-thinking financial industry that better serves society". The World Economic Forum emphasizes that "though ESG integration in investing decisions initially mostly applied to publicly listed equities, it is increasingly reflected in other asset classes and applied by a wider 
group of investors. This expansion indicates investors' willingness to consider non-financial metrics in investment decisions and a belief that such metrics may drive long-term risk mitigation and value, a perspective that in the past was not widely held". The UN PRI 2010 report states that "Externalities can affect shareholder value because they lead to a more uncertain, rapidly changing economic environment and greater systemic risks. Inefficient allocation of capital to highly polluting activities can cause a decline in asset values over time. For a diversified investor, environmental costs are unavoidable as they come back into the portfolio as insurance premiums, taxes, inflated input prices, and the physical cost associated with disasters. These costs could also reduce future cash flows and dividends. One company's externalities can damage the profitability of other portfolio companies, adversely affect other investments, and hence overall market return. Ultimately, externalities caused by companies could significantly affect the value of capital markets or their potential for growth, and with that, the value of diversified portfolios." In other words, longer-term risks of climate change and resource scarcity can be offset by investment tilts/themes towards companies with ESG-favorable drivers that should help portfolios outperform over the long term.

In general, existing literature shows that good corporate governance, sound environmental standards, and active engagement with stakeholders can create value for shareholders (Renneboog et al. 2008). Many researchers have studied the relationship between companies with strong ESG characteristics and corporate financial performance. According to such studies, (i) companies with a strong ESG profile are more competitive than their peers as they use resources, human capital and innovation more efficiently. Further, they are better at developing long-term business plans and long-term incentive plans for senior management. High ESG-rated companies tend to have lower exposure to systematic risk factors. Therefore, their expected cost of capital is lower, leading to higher valuations in a DCF model framework (Gregory et al. 2014; Eccles et al. 2011; El Ghoul et al. 2011; Dunn et al. 2016). (ii) Further, a study using stakeholder welfare score covering the employees, customers, communities, and environment of individual firms, noted that an increase of 1 in the stakeholder welfare score leads to an increase of 0.587 in Tobin's $Q$ (Jiao 2009). (iii) High ESG-rated companies are also better at managing company-specific business and operational risks and therefore have a lower probability of adverse incidents impacting their profitability and dividend distribution capacity. Consequently, their stock prices display lower idiosyncratic tail risks. Companies with strong ESG characteristics typically have above-average risk control and compliance standards across the company and within their supply chain management (Godfrey et al. 2009; Jo and $\mathrm{Na} 2012$ and Oikonomou et al. 2012). Additionally, Hong and Kacpercyk (2009) find that due to better risk control standards, high ESG-rated companies suffer less frequently from severe incidents such as fraud, embezzlement, corruption or litigation cases that can seriously impact the value of the company and therefore the company's stock price. Sustainability initiatives at corporations appear to drive better financial performance due to mediating factors such as improved risk management and more innovation, and become more noticeable over the long-term (Clark et al. 2021). The economic impact of sustainability practices shows lower cost of capital and better operational performance, positively influencing market valuation 
(Clark et al. 2015). Hoepner et al. (2013) call this an "insurance-like protection of firm value against negative events". They observed that high ESG-rated companies showed statistically significant lower downside risk measures such as volatility, lower partial moments and worst-case loss. A study on times series and cross-sectional firm-level return decomposition shows that good ratings on material sustainability issues significantly outperform firms with poor ratings (Khan et al. 2016). Moreover, high ESG-rated companies are typically more transparent, particularly with respect to their risk exposures, risk management and governance standards; hence, they attract a wider investor-base.

\section{Enhancing alpha}

Since a number of studies have been conducted in order to make a case for responsible investing and MSCI has already constructed various factor indices as well as such indices with an ESG tilt, in this study we have attempted to:

(i) analyze the risk characteristics of various indices developed by MSCI with the help of moments (standard deviation, variance, skewness and kurtosis); and

(ii) assess from investors' perspective: (a) to what extent they mimic or proxy the benchmark $\left(R^{2}\right)$, (b) to what extent they are influenced by factor risk (B) and (c) to what extent they can enhance excess return (a).

(iii) assess whether ESG overlay on factor based strategies enhance Alpha significantly or not.

\section{Data and their computational methodology}

We have used MSCI All Country World Index - as the Universe and within that, MSCI Factor Indices as well as MSCI Factor ESG Target Indices data from December 2007 to August 2020, as we believe that MSCI is one of the pioneers in developing a robust computational methodology by using both factor and ESG Metrics and rating technique for developing the various factor indices, including those with ESG tilt such as Value, Quality, Minimum Volatility and Multi-Factor indices. The MSCI All Country Index (Standard) currently captures large and mid-cap representation across 23 Developed Markets (DM) and 23 Emerging Markets (EM) countries and covers approximately $85 \%$ of the global investable equities. The MSCI Factor and Factor ESG Target Indices are constructed by factor weighting and reweighting stocks with a higher ESG Rating integrated with factor-based strategies such as Value, Quality, Minimum Volatility, and a combination of them from the MSCI Global Universe (GIMI), by following a target-specific factor exposure (i.e. Minimum Volatility, Quality, Value, etc.), screening and taking into consideration minimum 20\% ESG score improvement over the parent index ESG score, while maintaining active sector and country weights within $\mathrm{a} \pm 5 \%$ range to the parent index-for countries having higher than $2.5 \%$ weight in the parent index; 3 times 
of the weight in the parent index for countries with less than $2.5 \%$ weight, with an overall tracking error cap of $3 \%$.

\section{Value weighting criteria}

The value $z$-score for each security is calculated by combining the securitylevel exposures to two factors-Book-to-Price and Earnings Yield. A sector-relative $z$-score is derived from the combined $z$-score by standardizing the latter within each sector and winsorizing at \pm 3 standard deviation. Val$u e_{i}=(0.33) \times$ BtoP $_{i}+(0.67) \times$ Earnings Yield $_{i}$, based on the methodology adopted in MSCI Barra Global Equity Model for Long-Term Investors (GEMLTL).

\section{Quality weighting criteria}

The quality $z$-score for each security is calculated by combining in equal proportion, the security-level exposures to five factors-Profitability, Investment Quality, Earnings Quality, Leverage and Earnings Variability. A sector-relative $z$-score is derived from the combined $z$-score by standardizing the latter within each sector and winsorizing at \pm 3 standard deviation.

Quality $_{i}=(0.2) \times$ Profitability $_{i}+(0.2) \times$ Investment $_{\text {Quality }}+(0.2) \times$ Earnings Quality $_{i}+(-1) \times(0.2) \times$ Earnings $_{\text {Variability }}+(-1) \times(0.2) \times$ Leverage $_{i}$, based on the methodology adopted in MSCI Barra Global Equity Model for Long-Term Investors (GEMLTL).

\section{Low volatility weighting criteria}

The low volatility score for each security is calculated by combining in equal proportion the security-level exposures to two factors-Beta and Residual Volatility.

Low Volatility $_{i}=(-1) \times(0.5) \times$ Beta $_{i}+(-1) \times(0.5) \times$ Residual Volatility $_{i}$, based on the methodology adopted in MSCI Barra Global Equity Model for Long-Term Investors (GEMLTL).

\section{Multi-factor weighting criteria}

It is an equal-weighted combination of the value, quality, momentum and size signals.

All these indices are denominated in US Dollar. We have used the 1-month US Treasury Bill rate as the risk-free rate to run the CAPM regression.

\section{Research methodology}

Our research is designed based on the various market factors studied and models constructed so far, such as the Fama-French 3-factor model, the Carhart 4-factor 
model, the Fama-French 5-factor model and the Asness and Frazini's 6-factor model.

In line with our objective, we have first decomposed the factor characteristics of the indices, based on a hybrid 7-factor model, comprising size, value, momentum, profitability, investment, quality and low beta, as set out in our model mentioned below:

$$
\text { 7-factor model : } \begin{aligned}
R_{\mathrm{a}}= & R_{\mathrm{f}}+\left\{\beta_{\mathrm{mkt}} \times\left(R_{\mathrm{mkt}}-R_{\mathrm{f}}\right)\right\}+\left(\beta_{\mathrm{smb}} \times S M B\right)+\left(\beta_{\mathrm{hml}} \times H M L\right)+\left(\beta_{\mathrm{mom}} \times M O M\right) \\
& +\left(\beta_{\mathrm{rmw}} \times R M W\right)+\left(\beta_{\mathrm{cma}} \times C M A\right)+\left(\beta_{\mathrm{qmj}} \times Q M J\right)+\left(\beta_{\mathrm{bab}} \times B A B\right)+\alpha
\end{aligned}
$$

in which $R_{\mathrm{a}}=$ Asset return, $R_{\mathrm{f}}=$ Risk free return, $\beta_{\mathrm{mkt}}=$ Market loading factor (exposure to market risk, different from CAPM beta), $R_{\mathrm{mkt}}=$ Market return, $\beta_{\mathrm{smb}}=$ Size loading factor (the level of exposure to size risk), SMB $=$ Small Minus Big (The size premium), $\beta_{\mathrm{hml}}=$ Value loading factor (the level of exposure to value risk without the look-ahead bias), HML = High Minus Low (The value premium without the lookahead bias), $\beta_{\text {mom }}=$ Momentum loading factor (the level of exposure to momentum), $\mathrm{MOM}=\mathrm{Up}$ Minus Down (The momentum premium), $\beta_{\mathrm{rmw}}=$ Profitability loading factor, RMW = Robust Minus Weak (The profitability premium), $\beta_{\text {cma }}=$ Investment loading factor, $\mathrm{CMA}=$ Conservative Minus Aggressive (The investment premium), $\beta_{\mathrm{qmj}}=$ Quality loading factor, QMJ = Quality Minus Junk factor (The quality premium), $\beta_{\text {bab }}=$ Low Beta loading factor, $\mathrm{BAB}=$ Bet Against Beta factor (The low volatility premium) and $\alpha=$ Excess return over the benchmark.

After identifying and comparing the factor attributes, we have analyzed the performance of these indices in a market setting (ACWI as benchmark) with the help of Sharpe (1964) and Linter (1965)'s Capital Asset Pricing Model (CAPM) in order to derive excess return alpha $(\alpha)$ with the following regression equation:

$$
\text { CAPM : } R_{\mathrm{a}}=R_{\mathrm{f}}+\left\{\beta_{\mathrm{mkt}} \times\left(R_{\mathrm{mkt}}-R_{\mathrm{f}}\right)\right\}+\alpha
$$

where $R_{\mathrm{a}}=$ Asset return; $R_{\mathrm{f}}=$ risk free return; $\beta_{\mathrm{mkt}}=$ market loading factor (exposure to market risk, CAPM beta); $R_{\mathrm{mkt}}=$ market return.

We followed a Robust Linear Regression methodology and analyzed the significance of factor coefficients with $t$-stat ( $t$-statistic is a ratio of the departure of an estimated parameter from its notional value and its standard error); $p$ value ( $p$ value measures the statistical significance of the estimated parameter) and $R^{2}$ (Coefficient of determination) in analyzing the price return index data across all the indices under observation at $95 \%$ confidence level. We also looked at various descriptive statistics to analyze the behavior of these indices and the presence or absence of autocorrelation and heteroscedasticity in the data series. While absence of autocorrelation establishes that asset prices are random variables with no relationship with its past prices, absence of heteroscedasticity proves that the error term (residual) of a regression model can consistently predict the dependent variable across all values, or otherwise. The existence of heteroscedasticity is a major concern in the application of regression analysis, including the analysis of variance, as it can invalidate statistical tests of significance that assume that the modeling errors are uncorrelated and uniform, hence that their variances do not vary with the effects being modeled. 


\section{Analysis and interpretation}

We used monthly returns in the MSCI ALL COUNTRY WORLD (ACWIRTN), MSCI ACWI MINIMUM VOLATILITY (MINVOLRTN), MINIMUM VOLATILITY ESG TARGET (MINVOLESG), ACWI QUALITY (QLITYRTN), QUALITY ESG TARGET (QLTYESG), ACWI VALUE WEIGHTED (VALUERTN), VALUE ESG TARGET (VALUEESG), ACWI DIVERSIFIED MULTIPLE-FACTOR (MULTIRTN) and MULTIPLE-FACTOR ESG TARGET (MLTESGRTN) Indices from December 2007 to August 2020 for our study. All these are price return indices of standard (large and mid cap) and expressed in US Dollar. The descriptive statistics of these price return indices are presented in Table 1 and Fig. 1.

The above is supported by the descriptive statistics presented in Fig. 1.

It is noted from the descriptive statistics of the return series presented in Table 1 and Fig. 1 that the Minimum Volatility ESG Target (MINVOLESG) index has the lowest standard deviation, followed very closely by the Minimum Volatility index (MINVOLRTN), Quality index (QLITYRTN), Quality ESG Target (QLTYESG) index, the market benchmark All Country World Index (ACWIRTN), the Multifactor ESG Target (MLTESGRTN) index, the Multi-factor (MULTIRTN) index, the Value ESG Target (VALUEESG) index and the Value Index(VALUERTN), in that order. A closer look at the other moments, variance, skewness, kurtosis of the corresponding index series, shows that though all of them have negative skewness (i.e., a fat left tail or larger occurrence of negative returns than positive returns), the degree of negative skewness can explain the magnitude of chance outcomes of extremely negative returns. The degree of skewness shows that VALUERTN followed by QLITYRTN, QLTYESG, VALUEESG, ACWIRTN, MLTESGRTN, MULTIRTN, MINVOLRTN and MINVOLESG have lower downside risks, in that order. This conforms to previous findings of studies made by Ang et al. (2006), Zhang (2006), Barberis and Huang (2008) and Mitton and Vorkink (2007) that show a negative relationship between an asset's skewness and its return.

As far as kurtosis or the degree of steepness of the return distributions are concerned, the MULTIRTN has the highest peak with a kurtosis, closely followed by MINVOLRTN, MINVOLESG, MLTESGRTN, ACWIRTN, VALUERTN, QLTYESG, QLITYRTN and VALUEESG, in that order, which shows that the chances of relatively large values in amplitude may be more likely.

While zero $p$ values of $F$ stat shows that the index series are fit, we also noted the absence of autocorrelation and heteroskedasticity in our data points during the period under study, or in other words, such data points are independent and the noise or error terms of the dependent variable are the same across all values of the independent variables.

We then conducted factor regression test to understand the strength or weakness of indices based on the 7-factor model we used for the study.

The factor regression test results are presented in Table 2.

It is evident from the 7-factor regression data that the Quality ESG Target Index generated the highest Alpha of $12.95 \%$, followed closely by the Multi-Factor ESG Target Index at $12.04 \%$, the Quality Index at $11.37 \%$ and the Multi-Factor Index 


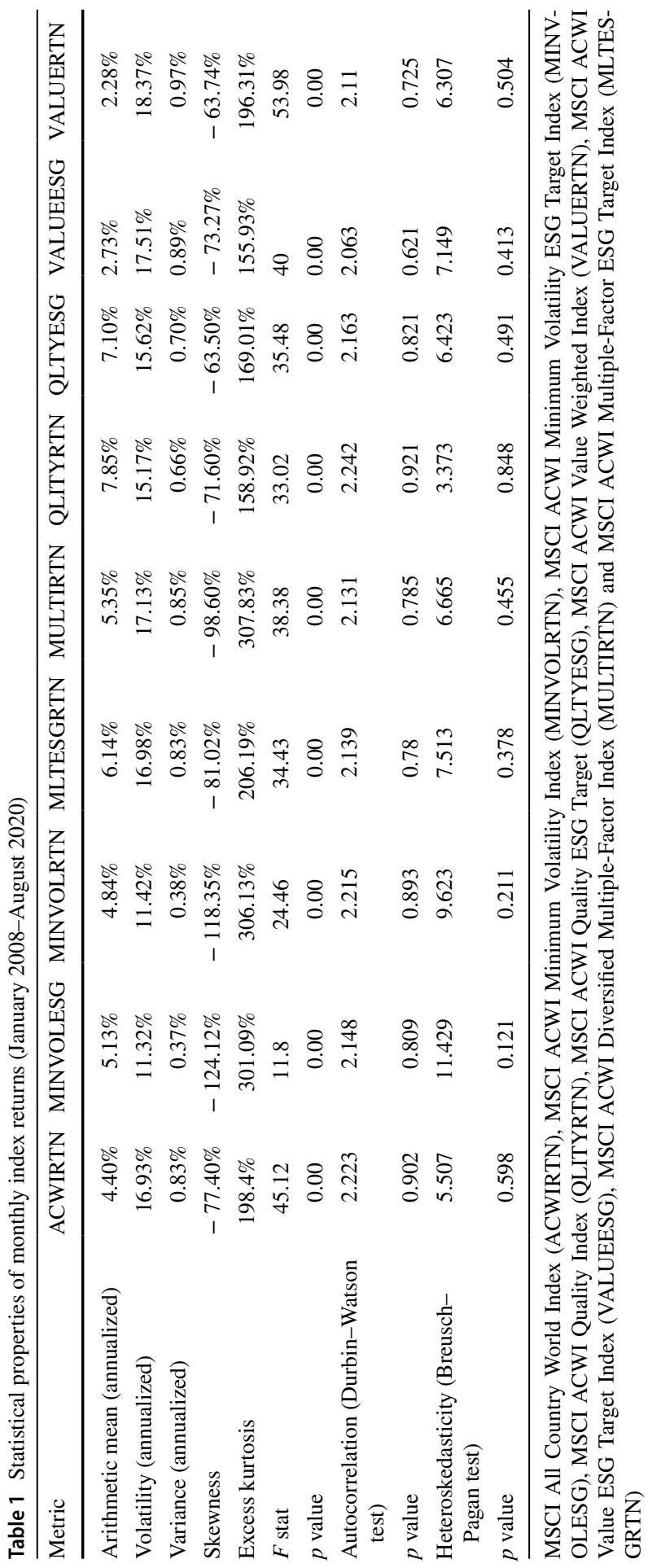

我这 


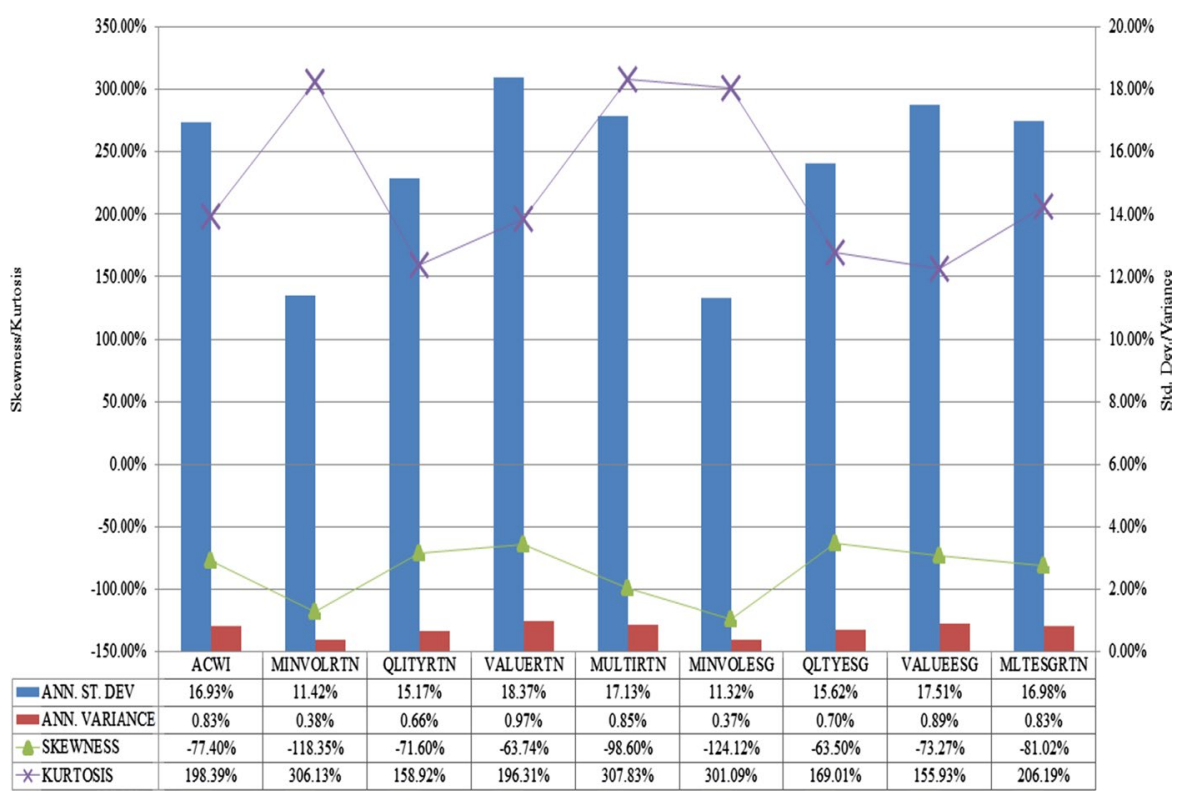

Fig. 1 Statistical properties of monthly index returns (January 2008-August 2020). MSCI All Country World Index (ACWIRTN), MSCI ACWI Minimum Volatility Index (MINVOLRTN), MSCI ACWI Minimum Volatility ESG Target Index (MINVOLESG), MSCI ACWI Quality Index (QLITYRTN), MSCI ACWI Quality ESG Target (QLTYESG), MSCI ACWI Value Weighted Index (VALUERTN), MSCI ACWI Value ESG Target INDEX (VALUEESG), MSCI ACWI Diversified Multiple-Factor Index (MULTIRTN) and MSCI ACWI Multiple-Factor ESG Target Index (MLTESGRTN)

at $10.62 \%$. Of the other indices, Value ESG had an Alpha of 10.09\%, nearly close to the Alpha of $10.11 \%$ in the case of ACWI, while the Value Index had an Alpha of 9.35\% and the Minimum Volatility ESG Target Index and Minimum Volatility Index lagged behind with an Alpha of 5.57\% and $4.98 \%$ respectively. However, in the case of all the ESG Target Indices, the ESG factor has generated comparatively higher Alpha than their underlying factor indices, the highest of $1.58 \%$ in the case of the Quality ESG Target Index, followed closely by the Multi-Factor ESG Target Index $(1.42 \%)$, the Value ESG Target Index $(0.74 \%)$ and the Minimum Volatility ESG Target Index (0.59\%). This clearly shows that an ESG Overlay on the various underlying market factors generates higher Alpha. Hence, the ESG overlay on some of the identified idiosyncratic cross-sectional risk factors, such as Value, Quality, Minimum Volatility and Multi-Factors-a combination of them and other factors such as Momentum and Size (not considered here individually), generate results that are clearly outstanding and significant.

The multi-factor decomposition provides us more insight into the cross-sectional aspects of these indices. We observed that the RMW (robust-minus-weak) or the profitability factor happens to be the most statistically significant market factor which added the highest premium to Alpha in basis points across all the indices. This was followed by very high, statistically significant and negative factor premium on account of the QMJ (quality-minus-junk) factor, which indicates 


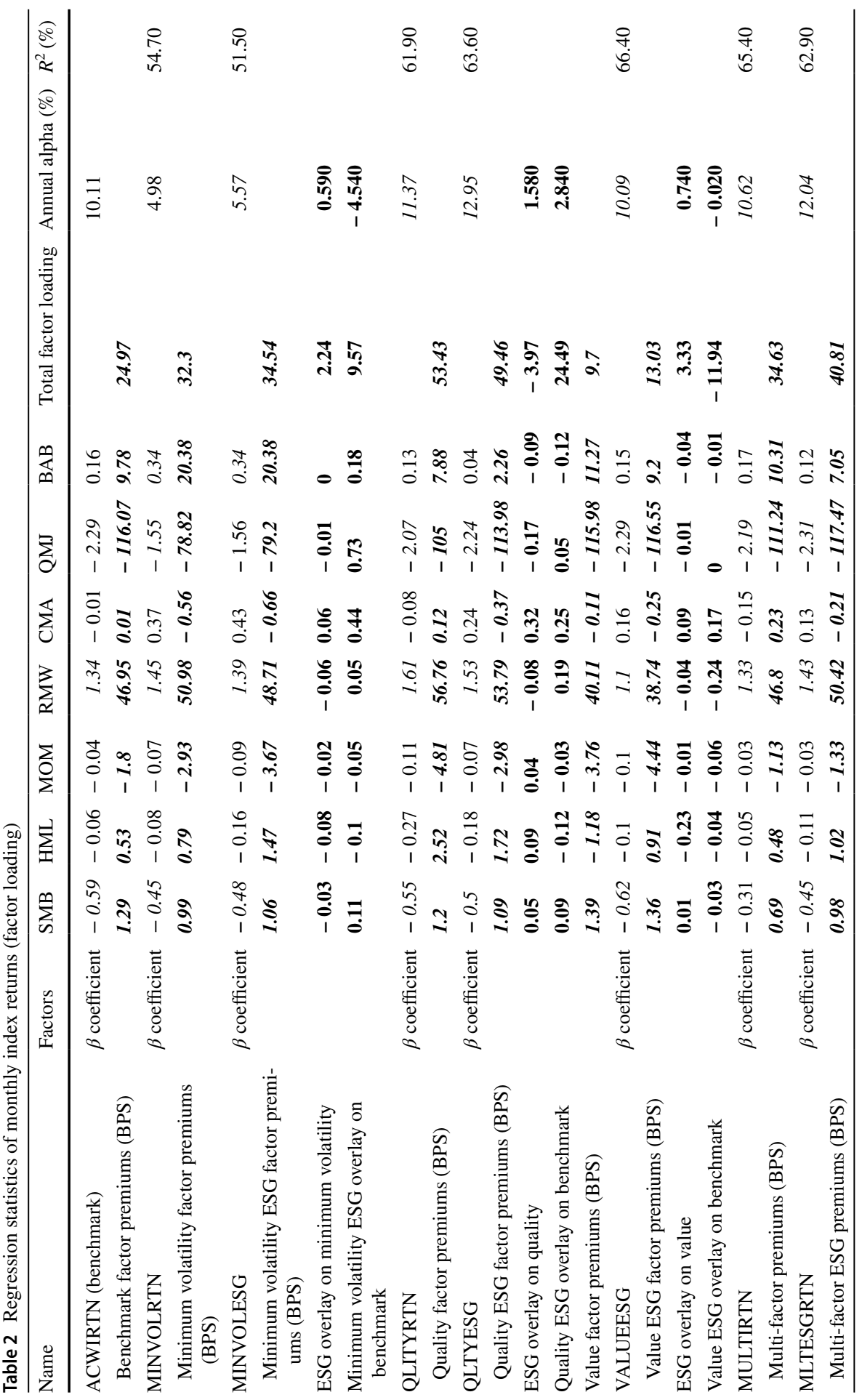




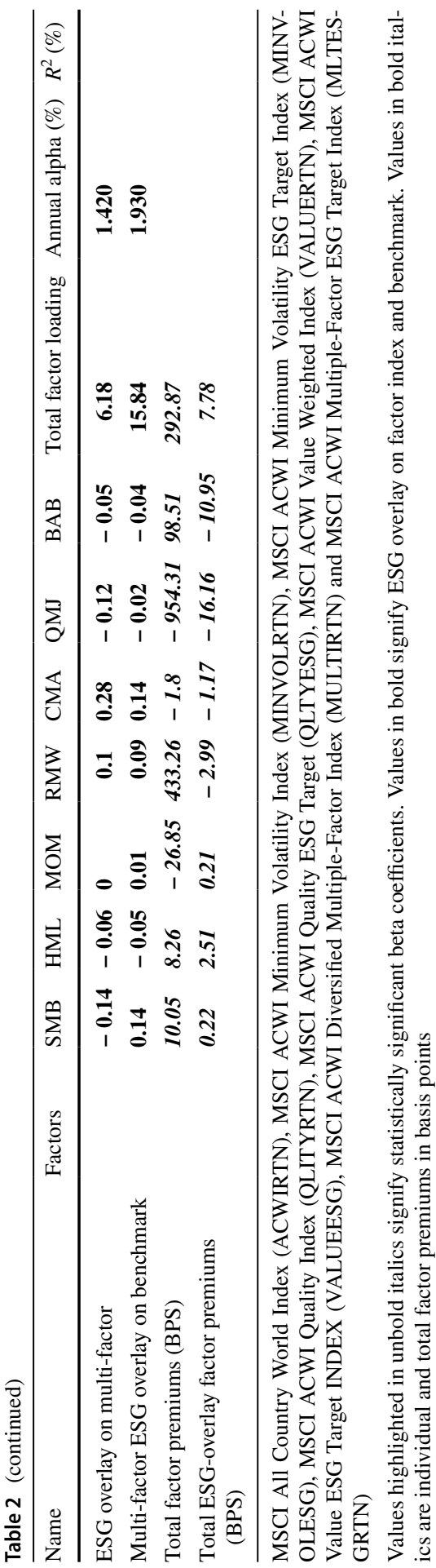


that the quality of the underlying companies is compromised to some extent when we add growth, both market and fundamental based volatility risk and higher payout ratios. The QMJ factor is slightly more compromised in the case of all ESG target indices with a comparatively lower factor premium in basis points. The third most important factor is SMB (small-minus-big) as its beta coefficient is negative and statistically significant across all the indices. This signifies that most of the underlying stocks in the factor as well as factor ESG indices are large in size. However, if we look at the factor premium loading of SMB, it is not very impressive as compared to other factors. Among the other 4 factors, the BAB (betting-against-beta) though having statistically significant beta only in the case of Minimum Volatility and Minimum Volatility ESG indices, has added the highest positive factor premia in basis points next only to RMW, across all the indices. However, the Minimum Volatility ESG Target index has some underlying stocks which are more prone to higher volatility. The other 3 factors HML (high-minuslow), MOM (momentum) and CMA (conservative-minus-aggressive) do not have statistically significant beta coefficients, though among them, a few basis points of factor premium get added due to the value factor, while the momentum factor scores some negative factor premium, leaving the impact of the investment factor negligible.

Among these indices, the Value Index mimics the benchmark or the ACWI, with the highest $R^{2}$ of $72.7 \%$, followed by the Value ESG Target Index at $66.4 \%$, the Quality ESG Target Index at 63.6\%, the Multi-Factor Index at 65.4\%, the Multi-Factor Target Index at 62.9\%, the Quality Index at $61.9 \%$, the Minimum Volatility Index at $54.7 \%$ and the Minimum Volatility ESG Target Index at $51.5 \%$.

The alpha values against factor beta of various return series presented in Figs. 2 and 3 show that market risk can be reduced to a great extent and alpha

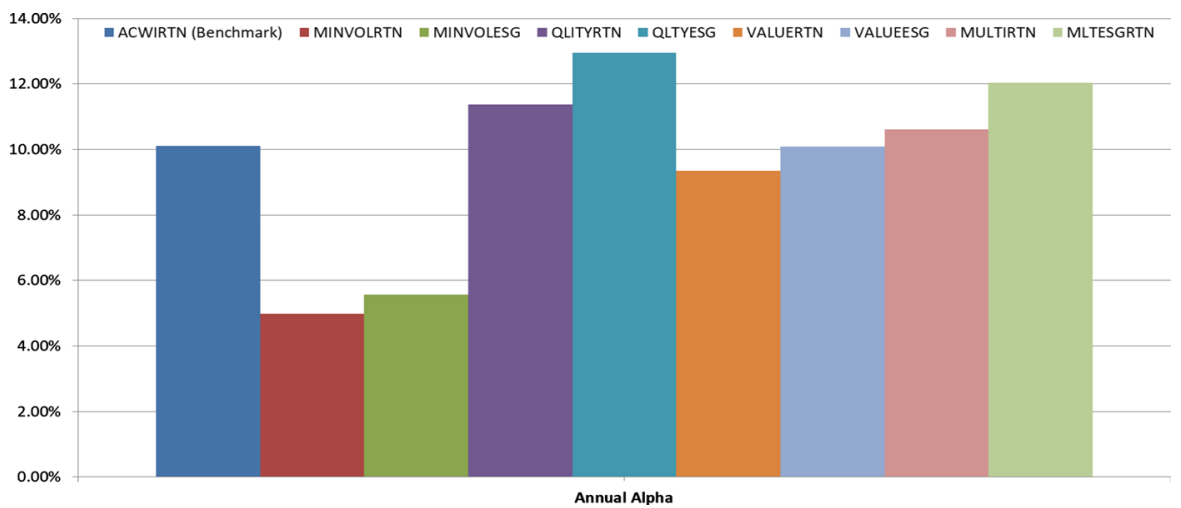

Fig. 2 Annualized excess return $(\alpha)$ of MSCI index return series. MSCI All Country World Index (ACWIRTN), MSCI ACWI Minimum Volatility Index (MINVOLRTN), MSCI ACWI Minimum Volatility ESG Target Index (MINVOLESG), MSCI ACWI Quality Index (QLITYRTN), MSCI ACWI Quality ESG Target (QLTYESG), MSCI ACWI Value Weighted Index (VALUERTN), MSCI ACWI Value ESG Target INDEX (VALUEESG), MSCI ACWI Diversified Multiple-Factor Index (MULTIRTN) and MSCI ACWI Multiple-Factor ESG Target Index (MLTESGRTN) 


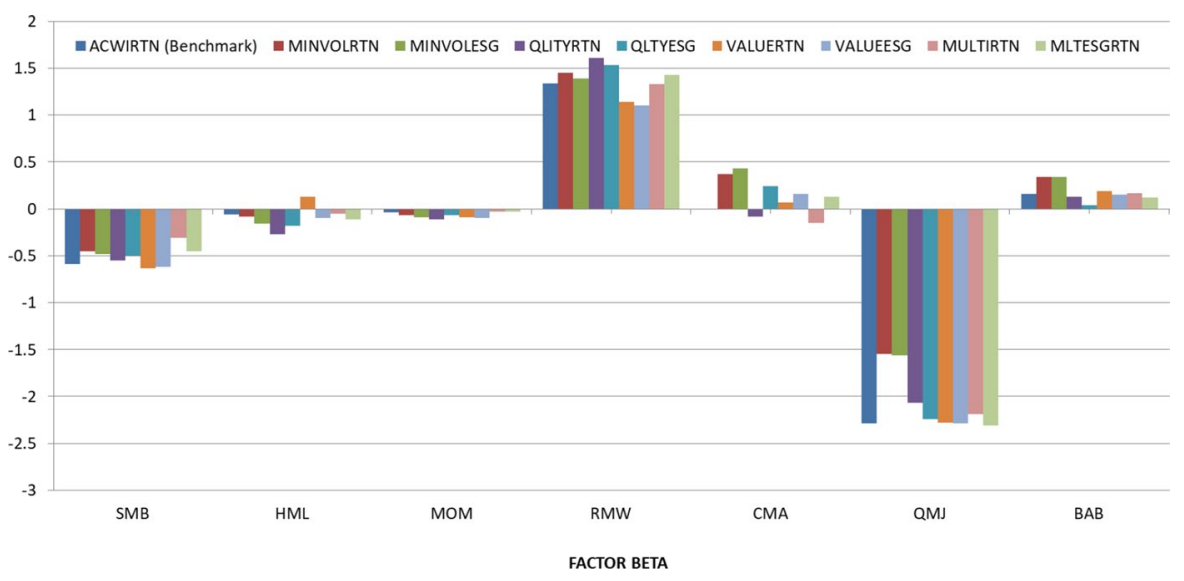

Fig. 3 Annualized factor risk $(\beta)$ of MSCI index return series. MSCI All Country World Index (ACWIRTN), MSCI ACWI Minimum Volatility Index (MINVOLRTN), MSCI ACWI Minimum Volatility ESG Target Index (MINVOLESG), MSCI ACWI Quality Index (QLITYRTN), MSCI ACWI Quality ESG Target (QLTYESG), MSCI ACWI Value Weighted Index (VALUERTN), MSCI ACWI Value ESG Target INDEX (VALUEESG), MSCI ACWI Diversified Multiple-Factor Index (MULTIRTN) and MSCI ACWI Multiple-Factor ESG Target Index (MLTESGRTN)

can be enhanced further with an ESG tilt over stocks with 'quality', followed by 'multi-factor', 'value' and 'minimum volatilty, in that order.

Thus, we believe that larger companies which follow stricter ESG principles and practices have built up better resistance to systematic market shocks, their financials are more predictable than others, they earn a higher equity premium and hence have a lower cost of capital.

\section{Index investing strategies}

With a view to making our findings more robust and investor-centric, we invest a notional \$10 million in each of these investible indices, starting from January 2008, and remain invested till August 2020. We backtested their performance, using the 3-month US treasury bill rate as the risk-free rate. We measured their performance against the ACWI as the benchmark, following the market factor model. The dollar value of the investments in these indices over the above-mentioned period, is presented below and their annualized returns are presented in Fig. 4 and Table 3 respectively.

Interestingly and contrary to our expectations, we get a mixed result in a market setting (refer to ACWI as the benchmark). The Quality index provides the highest value of $\$ 23,280,000$ with an annualized return of $8.14 \%$, followed by the Quality ESG Target index value of $\$ 20,990,000$ with an annualized return of $7.34 \%$, Multi-Factor ESG Target index value of $\$ 18,049,000$ with an annualized return of $6.32 \%$, Minimum Volatility ESG Target index value of $\$ 17,605,000$ with an annualized return of $5.25 \%$, Minimum Volatility index value of $\$ 16,967,000$ with an 


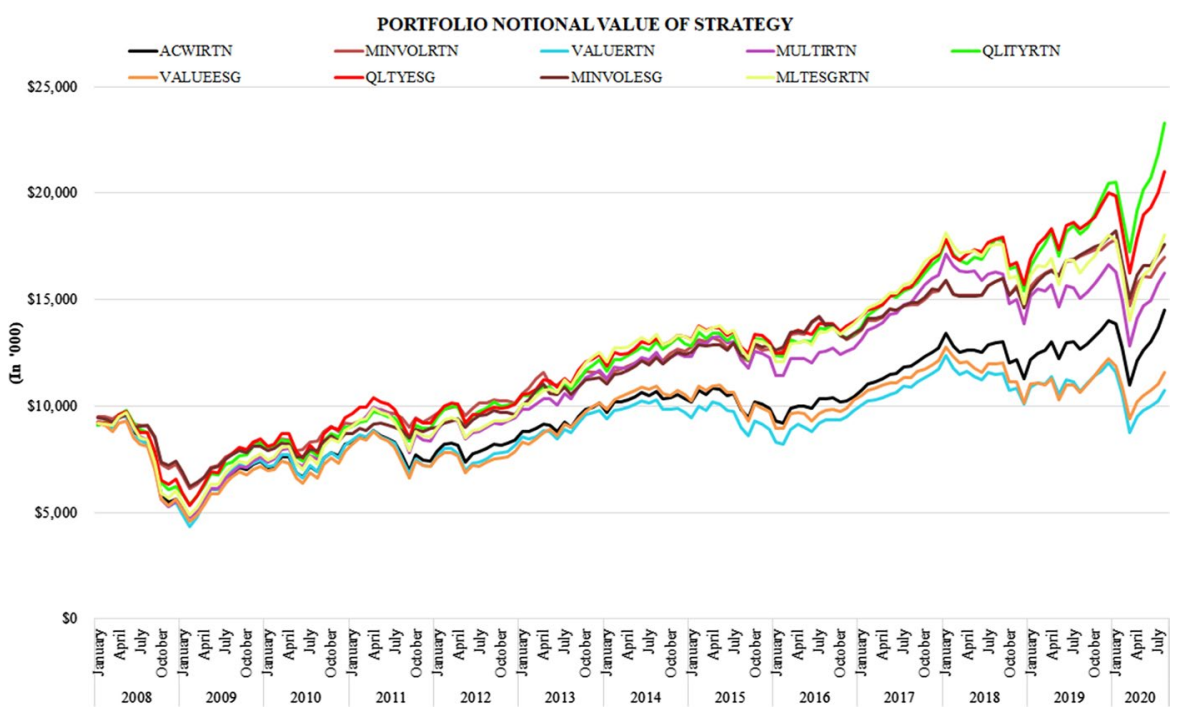

Fig. 4 Performance of strategy indices-monthly trend. MSCI All Country World Index (ACWIRTN), MSCI ACWI Minimum Volatility Index (MINVOLRTN), MSCI ACWI Minimum Volatility ESG Target Index (MINVOLESG), MSCI ACWI Quality Index (QLITYRTN), MSCI ACWI Quality ESG Target (QLTYESG), MSCI ACWI Value Weighted Index (VALUERTN), MSCI ACWI Value ESG Target INDEX (VALUEESG), MSCI ACWI Diversified Multiple-Factor Index (MULTIRTN) and MSCI ACWI Multiple-Factor ESG Target Index (MLTESGRTN)

annualized return of $4.95 \%$, Multi-Factor index value of $\$ 16,248,000$ with an annualized return of $5.48 \%$, the ACWI index value of $\$ 14,504,000$ with an annualized return of $4.49 \%$, Value ESG Target index value of $\$ 11,586,000$ with an annualized return of merely $2.76 \%$ and Value index value of $\$ 10,727,000$ with an annualized return of $2.3 \%$. Not withstanding the above, all the ESG target indices have provided higher values compared to their underlying factor indices, except the Quality ESG Target index, though the latter has generated the highest value among all the ESG target indices, while the ESG impact is positive over Multi-Factor, Minimum Volatility and Value overlays. This is a reaffirmation of our previous findings that some quality is compromised due to the ESG impact, a view explained in a recent study that the maximum Sharpe ratio is achieved for a relatively high level of ESG. However, increasing the ESG level even further, leads to only a small reduction in Sharpe ratio, implying that ethical goals can be achieved at a small cost, indicating higher risk aversion of investors who prefer to invest in stocks with higher ESG scores but marginally lower Sharpe ratio (Pedersen et al. 2020).

\section{Performance measurement and attribution analysis of strategies}

We measured the performance of these indices with various attributions such as Alpha, Beta, annualized volatility and Maximum Drawdown, Upside and Downside Capture ratios; Information ratio, Sharpe ratio, Sortino ratio, Treynor ratio and 


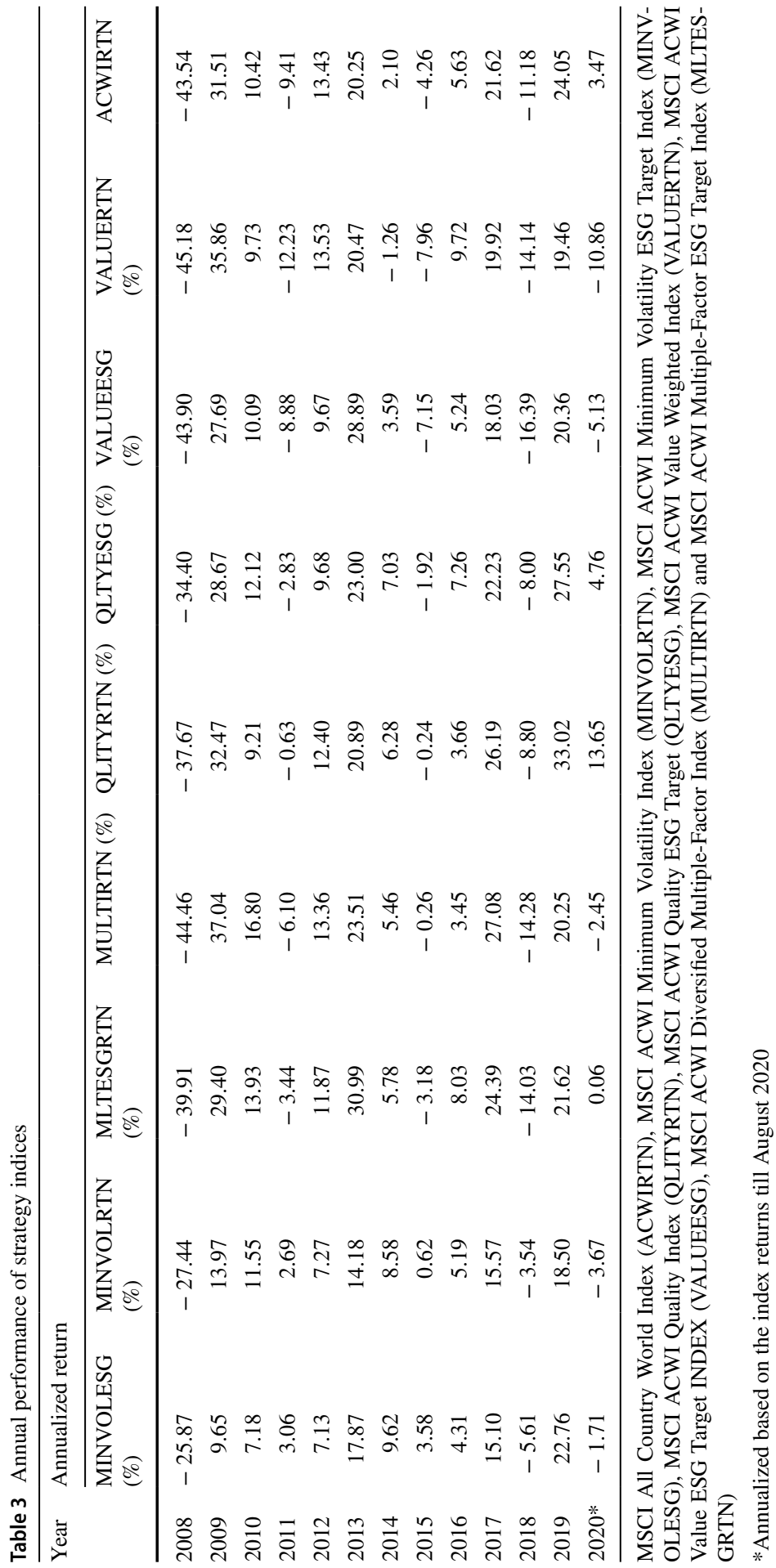


Calmar ratio; Rolling 36-month Factor Regression and Maximum Drawdown analysis during the investment period. These are presented in Table 4 and Fig. 5.

The Quality index has the highest alpha (4\%), followed by the Quality ESG Target index (3.1\%), Minimum Volatilty ESG Target index (2.47\%), Minimum Volatilty index (2.15\%), Multi-Factor ESG Target index (1.79\%), Multi-Factor index (0.96\%), Value ESG Target index $(-1.73 \%)$ and Value index $(-2.44 \%)$, in that order.

Typically, in a market setting (refer to ACWI as the benchmark), most of these indices track the market very closely, except for the Minimum Volatility and Minimum Volatily ESG target indices which have the highest tracking error of $8.33 \%$ and $8.11 \%$, respectively. These two indices have the lowest annualized volatility of $11.42 \%$ and $11.32 \%$ and the lowest maximum drawdown of $37.66 \%$ and $38.64 \%$, respectively. They also have the lowest downside and upside capture ratios of $54.92 \%$ and $54.93 \%, 62.29 \%$ and $61.01 \%$; and lowest beta of 0.6 and 0.61 , respectively. Both, the Value index and the Value ESG Target index are the worst affected by market conditions, displaying highest volatility $(17.51 \%$ and $17.31 \%)$, higher market beta (1.07 and 1.01), maximum drawdowns of $(56.43 \%$ and $54.33 \%)$ and highest downside and upside capture ratios $(111.87 \%$ and $106.48 \% ; 101.6 \%$ and $98.55 \%$, leading to negative alphas $(2.44 \%$ and $1.73 \%)$, respectively. The Quality ESG Target index tracks the market a little closely (3.18\% as against $3.85 \%$ ), picks up a few basis points of additional volatility (15.62\% as against $15.17 \%$ ), has slightly higher maximum drawdown (46.75\% as against $46.17 \%$ ), a relatively higher beta (0.91 as against 0.88 ), a comparatively higher downside capture ratio $(84.97 \%$ as against $81.54 \%$ ) and a slightly lower upside capture ratio (98\% as against $98.36 \%$ ) as compared to its underlying Quality index.

The Multi-Factor index follows the market very closely and has attributes which are very close to those of ACWI-the market benchmark, whereas, the Multi-Factor ESG Target index has comparatively much better attributes, with less volatility $(16.98 \%$ as against $17.13 \%)$ and lower maximum drawdown $(51.16 \%$ as against $53.1 \%)$, a slightly lower beta (0.99 as against 1$)$, comparatively higher upside capture ratio (102.9\% as against $100.06 \%)$ and a lower downside capture ratio $(94.98 \%$ as against $96.06 \%$ ), than its underlying Multi-Factor index.

Among these indices, the quality index has the highest information ratio (1.02), Sharpe ratio (0.48), Sortino ratio (0.68), Treynor ratio (8.28\%) and Calmar ratio (0.9), followed closely by the Quality ESG Target index with an information ratio (0.96), Sharpe ratio (0.41), Sortino ratio (0.59), Treynor ratio $(7.15 \%)$ and Calmar ratio (0.55). This shows that quality is the most important factor in a market setup, that can generate excess return compared to the benchmark, captures the lowest downside risk, captures the higest rewards from volatility, is a better revival indicator post market downturns and can provide higher average compounded annual return against maximum drawdowns, over a period.

Next to Quality and Quality ESG Target indices, the Multi-Factor ESG Target index has slightly better performance ratios as compared to its underlying counterpart, though the Minimum Volatility ESG Target and Minimum Volatility indices are better in terms of their ability to revive post market downturns and provide better average compounded annual return against maximum drawdowns, over a period. This also reaffirms that though Minimum Volatility and Minimum Volatility ESG 


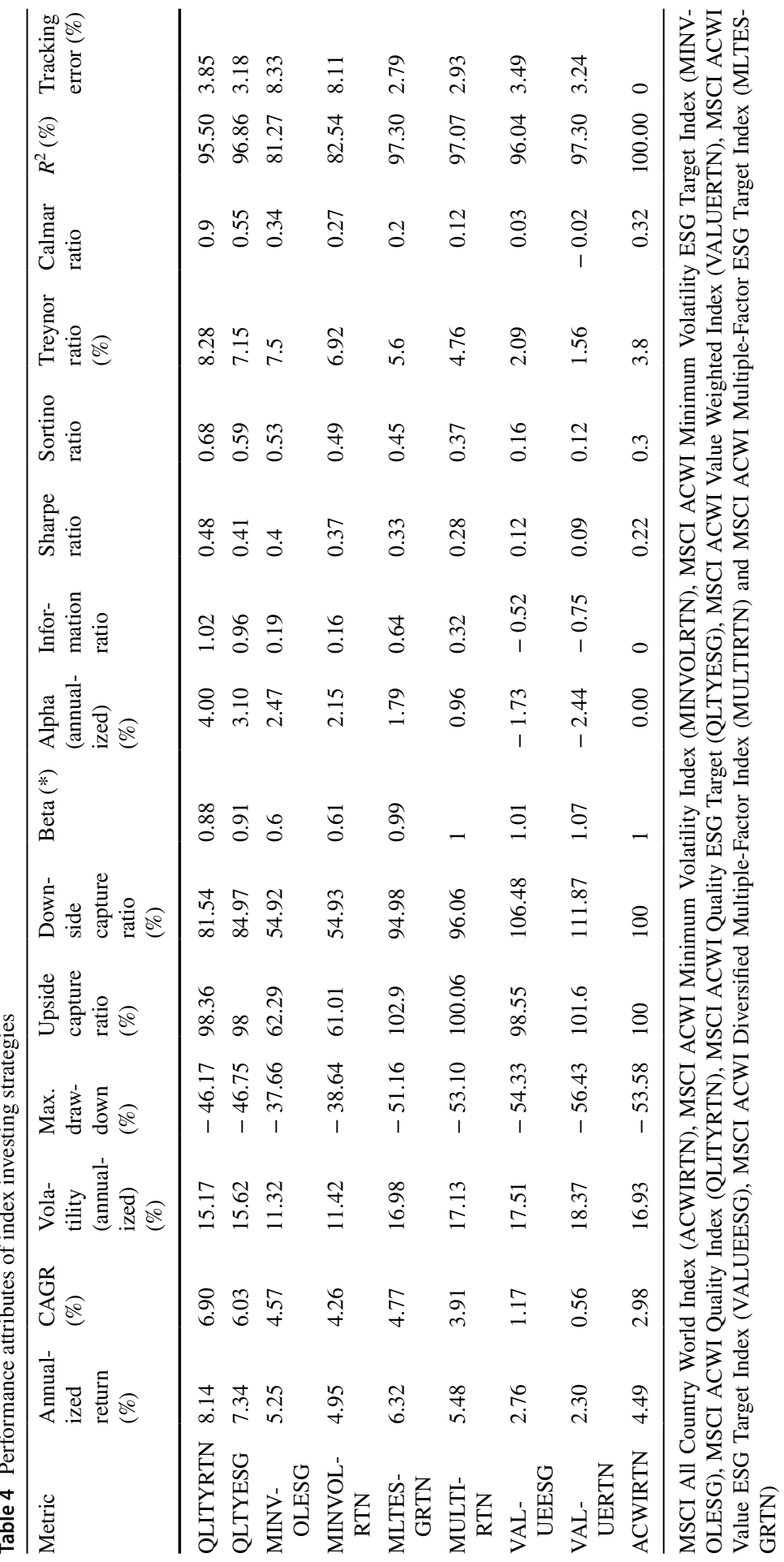




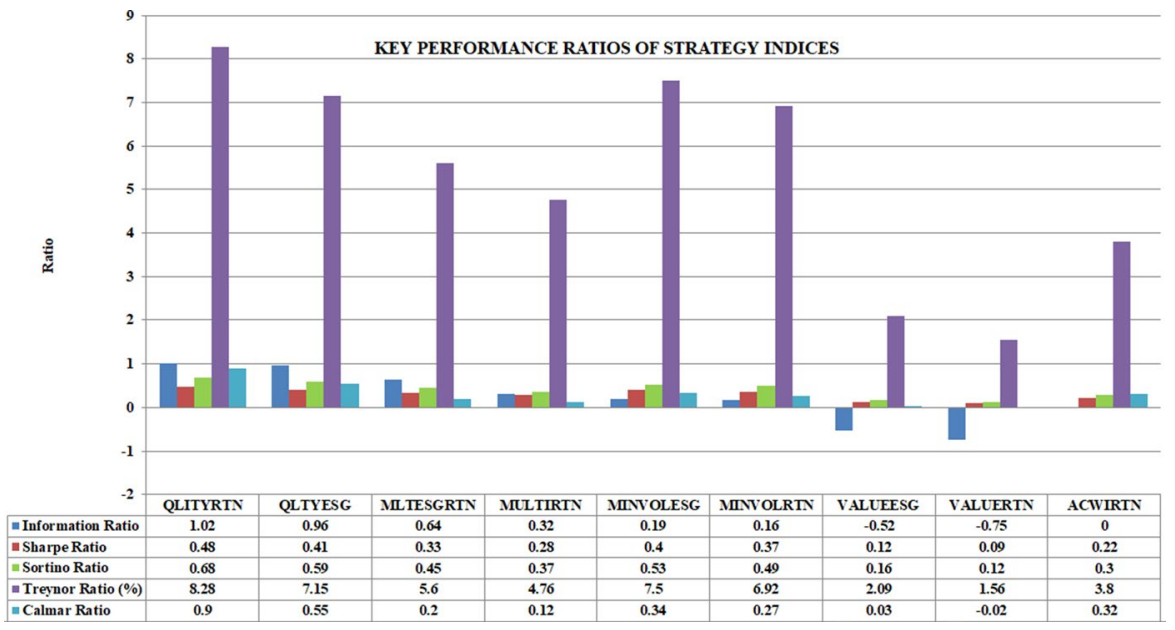

Fig. 5 Key performance ratios of index investing strategies. MSCI All Country World Index (ACWIRTN), MSCI ACWI Minimum Volatility Index (MINVOLRTN), MSCI ACWI Minimum Volatility ESG Target Index (MINVOLESG), MSCI ACWI Quality Index (QLITYRTN), MSCI ACWI Quality ESG Target (QLTYESG), MSCI ACWI Value Weighted Index (VALUERTN), MSCI ACWI Value ESG Target INDEX (VALUEESG), MSCI ACWI Diversified Multiple-Factor Index (MULTIRTN) and MSCI ACWI Multiple-Factor ESG Target Index (MLTESGRTN)

Target indices may provide lowest alphas in a multi-factor model regression, they are indeed better in terms of downside risk protection.

Both Value ESG Target and Value indices have negative information ratio, as they are more prone to market risk, overeact to market downslides and respond slowly to market revivals.

\section{All weather test}

In order to reaffirm the above and get further insights into how the various indices behave during different market conditions, we conducted a 36-month Rolling Regression and have presented the rolling alphas and betas in Figs. 6 and 7, respectively. We noted that both the alpha and beta values of these indices change significantly over time, as the factor betas are influenced to a varying degree depending upon the market conditions.

The above trends in alpha in conjunction with difference in beta variations due to ESG overlay on underlying indices in 36-month rolling regression presented in Fig. 7 provide us a deeper and granular understanding of where and to what extent ESG overlay contributes or reduces risk over their underlying indices.

The average of beta variations show that ESG overlay has made positive contribution to the value (0.0386), momentum (0.0477), quality $(0.0818)$ and low volatility factors $(0.0283)$, while it has enhanced risk to size $(-0.0901)$, profitability $(-0.199)$ and investment factors $(-0.0786)$ in the case of underlying Minimum Volatility index. As far as ESG overlay on the underlying Multi-factor index is 


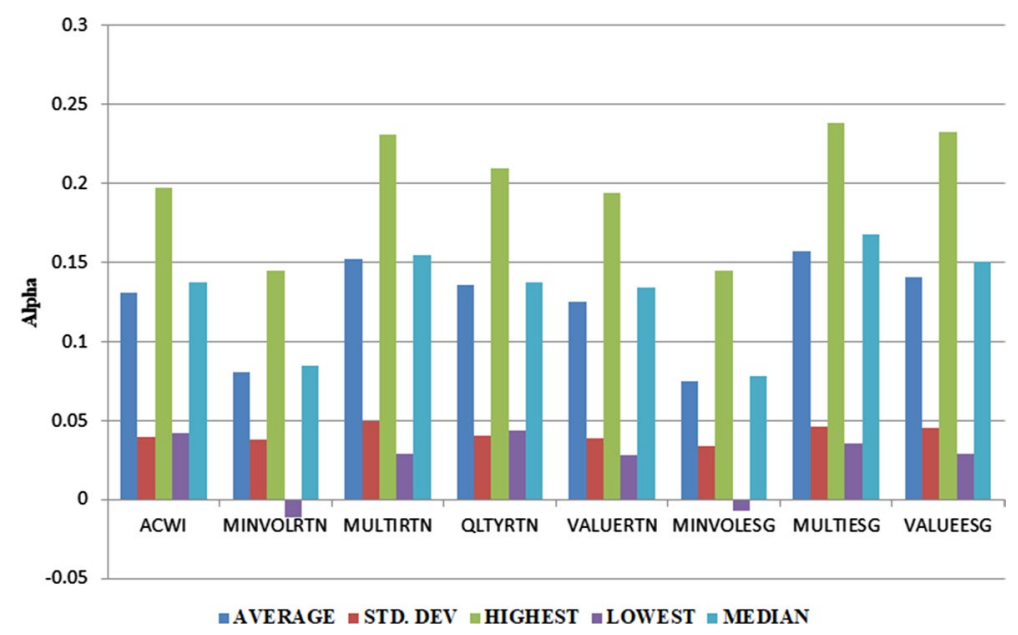

Fig. 6 Alpha variations in 36-month rolling regression. MSCI All Country World Index (ACWIRTN), MSCI ACWI Minimum Volatility Index (MINVOLRTN), MSCI ACWI Minimum Volatility ESG Target Index (MINVOLESG), MSCI ACWI Quality Index (QLITYRTN), MSCI ACWI Quality ESG Target (QLTYESG), MSCI ACWI Value Weighted Index (VALUERTN), MSCI ACWI Value ESG Target INDEX (VALUEESG), MSCI ACWI Diversified Multiple-Factor Index (MULTIRTN) and MSCI ACWI Multiple-Factor ESG Target Index (MLTESGRTN)

concerned, it has made positive contributions to value (0.0178), momentum (0.021), profitability (0.0094) and investment $(0.2689)$ factors, but has enhanced risk in the case of size $(-0.119)$, quality $(0.0063)$ and low volatility $(-0.0643)$ factors. Similarly, the ESG overlay on the Quality index has made positive contributions to size (0.1105), value (0.0544), momentum (0.0797) and investment (0.3726) factors, while it has added higher risk in terms of profitability $(-0.0968)$, quality $(-0.075)$ and low volatility $(-0.203)$ factors. In the case of ESG overlay on the Value index, risk has got further accentuated in the size $(-0.0463)$, value $(-0.1143)$, momentum $(-0.0143)$, profitability $(-0.019)$, quality $(-0.0359)$ and low volatility factors, except for the investment (0.0701) factor. The positive ESG impact to the investment factor is highly pronounced in the case of underlying Quality (0.3726) and Multifactor (0.2689) indices. Similarly, the study shows that ESG overlay has reduced risk by bringing down the highest beta variations in the case of profitability (0.07), investment (0.62), quality (0.01) and low volatility (0.06) factors of the underlying Minimum Volatility index; profitability (0.43) and quality (0.29) factors in Multifactor index; low volatility (0.21) factor in Quality index and in all the factors in the case of the Value index. The ESG overlay has further reduced the downside risk to all the market factors in the case of all the underlying indices. The median values also support the above findings in all the market factors, excepting the value factor. Similarly, the standard deviation of beta variations across all the market factors is less pronounced due to ESG overlay in the case of the underlying Minimum Volatility and Quality indices. As far as the standard deviation of ESG overlay impact over the various market factors, it is less pronounced: in the size factor in all the underlying indices except for the Multi-factor index; in the value and profitability factors 
VARIATIONS IN AVERAGE FACTOR BETA
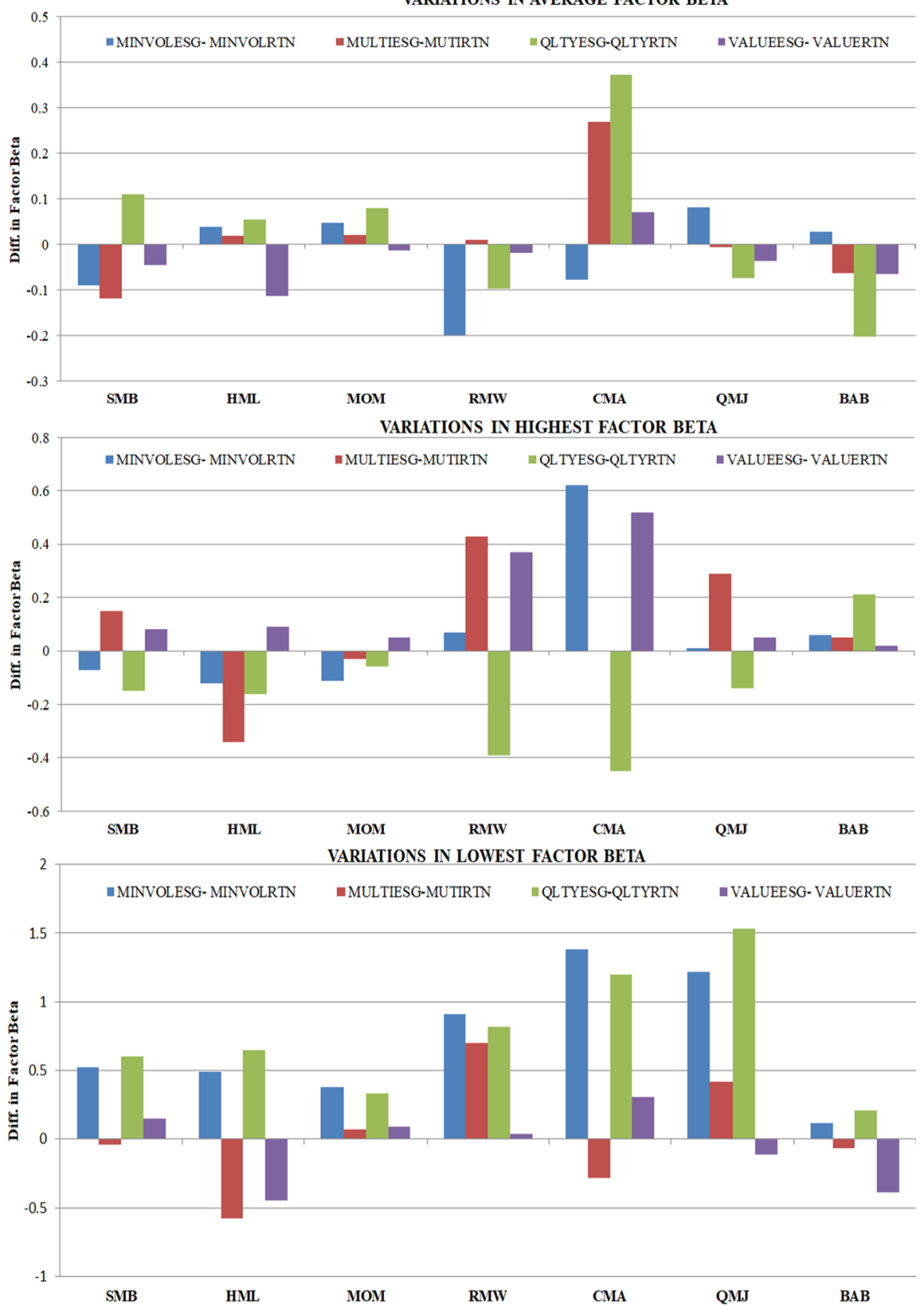

Fig. 7 Difference in beta variations in 36-month rolling regression. MSCI All Country World Index (ACWIRTN), MSCI ACWI Minimum Volatility Index (MINVOLRTN), MSCI ACWI Minimum Volatility ESG Target Index (MINVOLESG), MSCI ACWI Quality Index (QLITYRTN), MSCI ACWI Quality ESG Target (QLTYESG), MSCI ACWI Value Weighted Index (VALUERTN), MSCI ACWI Value ESG Target INDEX (VALUEESG), MSCI ACWI Diversified Multiple-Factor Index (MULTIRTN) and MSCI ACWI Multiple-Factor ESG Target Index (MLTESGRTN)

s.t. 

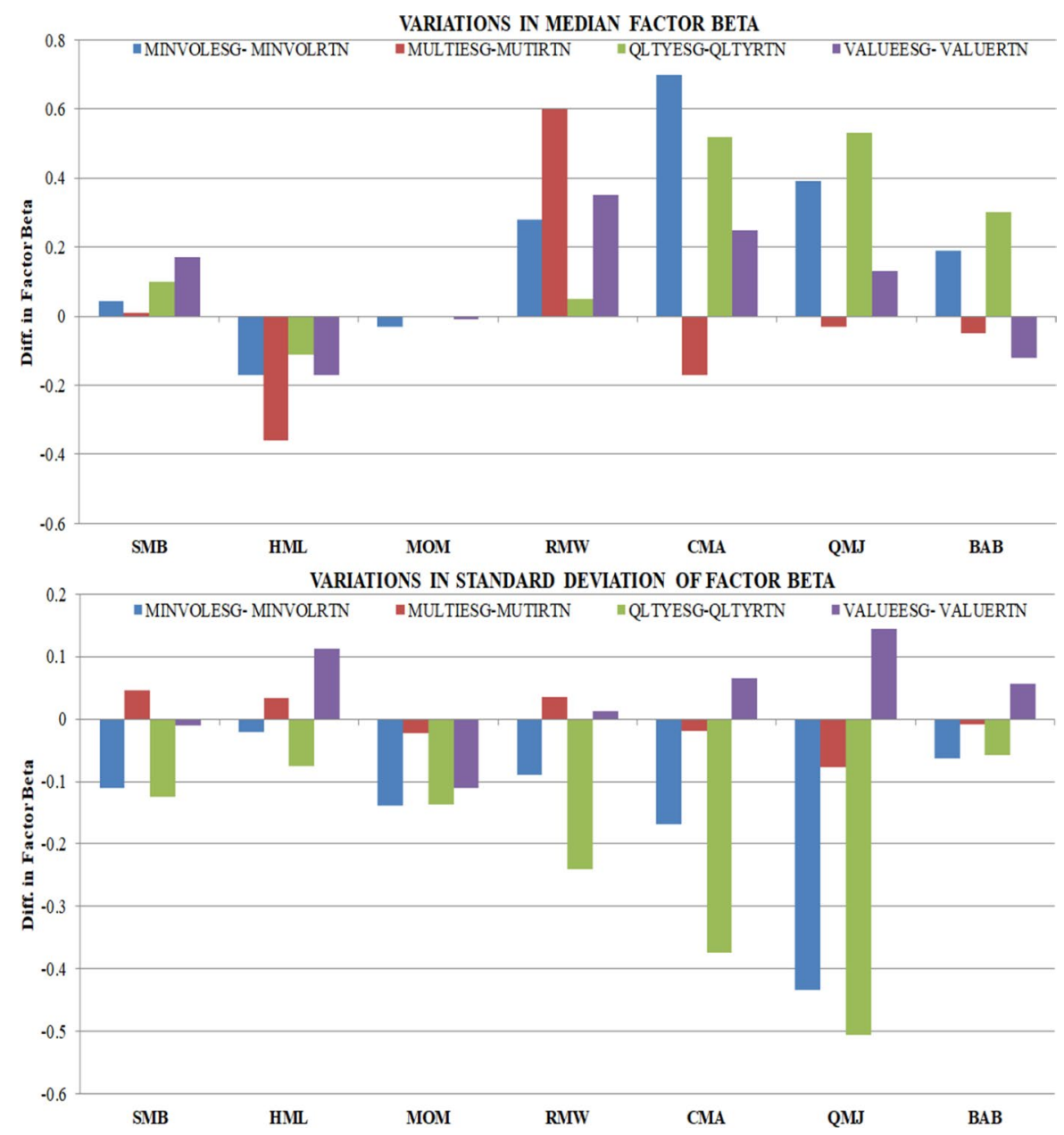

Fig. 7 (continued)

in the underlying Minimum Volatility and Quality indices; in the momentum factor across all underlying indices; in the investment, quality and low volatility factors in the case of all the underlying indices, excepting the Value index.

Overall, we conclude that the positive impact (capturing upside potential) of ESG overlay on the underlying indices is pronounced in the profitability, investment, quality and low volatility factors, and to a lesser extent in the size and momentum factors. However, it has negatively impacted the value factor. It shows that both Quality and Quality ESG Target indices are highly responsive to the RMW, that is, the underlying stocks respond faster to a market revival as they are profitable and to some extent they also have slightly lower volatility as compared to the market. These two indices are followed by the Multi-Factor and Multi-Factor ESG Target indices, as far as the RMW and BAB factors are concerned. Typically, while the Minimum 
Volatility and Minimum Volatility Target ESG indices protect downside risk, they are also highly responsive to a revival from a downturn and count positively on the CMA factor. The Value and Value ESG Target indices are slow in response to market revival and can only count on HML and RMW factors.

\section{Trends in downside risk}

The details of periodic downside risk associated with the various indices during different market conditions, are presented in Table 5.

Taking a wholesome account of market conditions, we observed that the gain/ loss ratio was highest for the Quality and Quality ESG Target indices at 0.94 and 0.91 respectively, followed by the Value index at 0.89 , Minimum Volatility ESG Target index at 0.85 , the Minimum Volatility index at 0.84 , the Multi-Factor ESG Target index at 0.84, the Multi-Factor index at 0.83 and the Value ESG Target index at 0.82. The Minimum Volatility and the Minimum Volatility ESG Target indices had the highest number of positive periods (95 out of 152 months), followed by the Quality ESG Target, Quality and Multi-Factor ESG Target indices (93 out of 152 months), Multi-Factor index (92 out of 152 months), Value ESG Target index ( 88 out of 152 months) and Value index ( 84 out of 152 months), while the market had 91 positive periods out of 152 months. Hence, if we consider the upsides of market movements, ESG overlay has some additional positive impact compared to their underlying factor indices.

It shows that remaining invested in the market is about exposure to market risks to a varying degree depending on the nature of the underlying securities in an index. Through the period of January 2008 to February 2009, during the initial phase of the global financial crisis, the ACWI was down by $53.58 \%$, even more pronounced in the case of both - the Value $(-56.43 \%)$ and Value ESG $(-54.33 \%)$ indices, while the Multi-Factor and Multi-Factor ESG Target indices closely followed the market at $-53.1 \%$ and $-51.16 \%$. The indices that were impacted to a slightly lesser extent were the Quality ESG Target and the Quality indices by $-46.75 \%$ and $-46.17 \%$, respectively; while the Minimum Volatility ESG Target and Minimum Volatility indices in terms of their ability to withstand market downslides, were significantly lower at $-37.66 \%$ and $-38.64 \%$, respectively. The second major drawdown period was during the initial phase of the COVID-19 outbreak. During January to March 2020, the market drawdown was $-23.11 \%$ as measured by the fall in the ACWI, sharper at $-29.73 \%$ for the Value index and slightly lower at $-24.72 \%$ for the Value ESG Target index, further lower at $-24.66 \%$ for the Multi-Factor index, at $-23.76 \%$ for the Multi-Factor ESG Target Index, at $-19.84 \%$ for the Quality ESG Target index, at $-17.06 \%$ for the Minimum Volatility index, at $-16.50 \%$ for the Quality index and at $-16.32 \%$ for the Minimum Volatility ESG Target index. This shows that ESG overlay has also contributed in protecting downside risk in the case of the Minimum Volatility, Value and Multi-factor indices. While the Minimum Volatility ESG Target index recorded the lowest downside risk, the quality factor without ESG overlay was also quite close to it in protecting downside risk. 


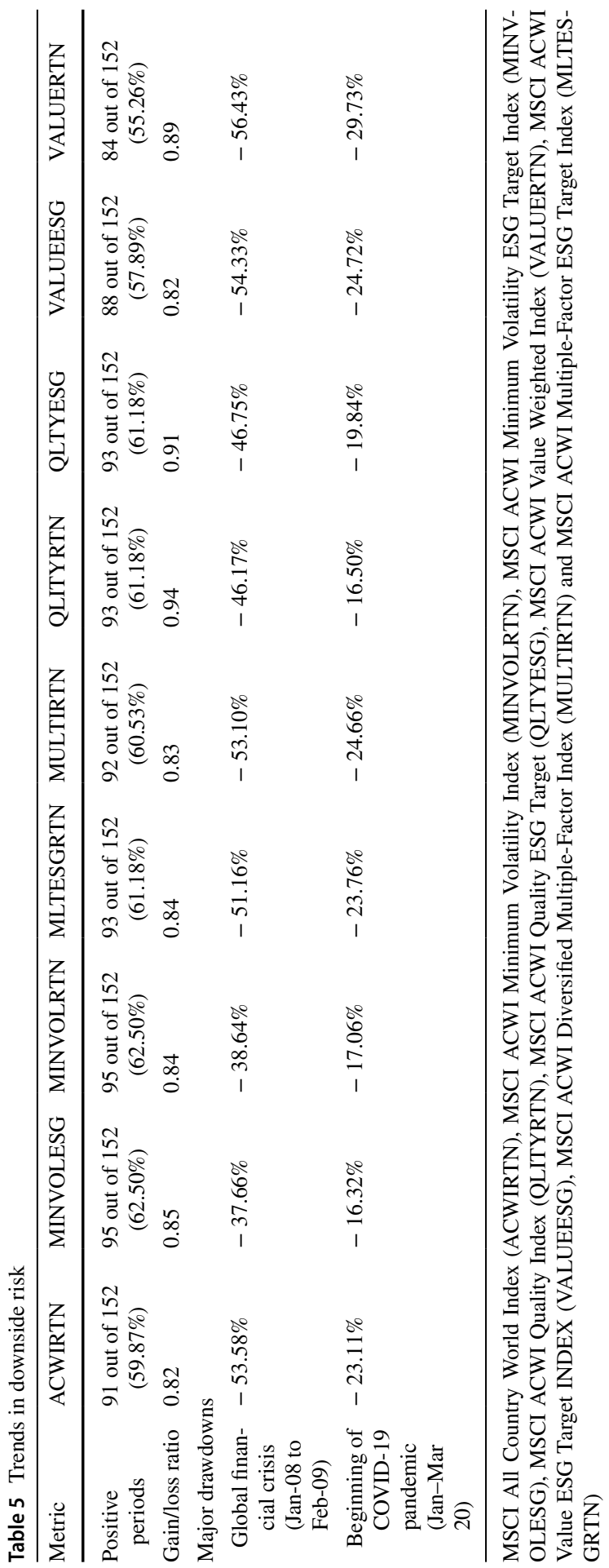




\section{Conclusion}

The descriptive and regression statistics as well as the performance measurement and attribution analysis parameters used in this study to understand and define risk, either relative to risk-free rate or a market benchmark or some of the identified factor risks, and to compare the risk-adjusted returns from the various strategy indices, show that there is no auto-correlation and heteroskedasticity in the return series studies and hence our results are robust.

As far as factor risks vis-à-vis premiums are concerned, we observed that RMW (robust-minus-weak) or the profitability factor, happens to be the most statistically significant market factor which added the highest premium to Alpha, in basis points across all the indices. The BAB (betting-against-beta) factor though only having statistically significant beta in the case of the Minimum Volatility and Minimum Volatility ESG indices, has added the highest positive factor premiums in basis points, next only to RMW across all the indices. The statistically significant and negative factor premium of the QMJ (quality-minus-junk) factor indicates that the quality of the underlying stocks in these indices is compromised to some extent, when we consider growth, both market and fundamental-based volatility risk, and higher payout ratios. The third most important factor is SMB (small-minus-big) as its beta coefficient is negative and statistically significant across all the indices, signifying that most of the underlying stocks in the factor as well as in the factor ESG indices are large in size. Other factors have negligible factor premiums.

ESG Overlay on factor-based indices provides higher factor premiums across all the indices studied, except for the Quality factor index. We also believe that as far as quality is concerned, adherence to ESG criteria may have come at a cost to quality of the underlying stocks to some extent-as is evident from the higher QMJ negative factor premiums of ESG indices as compared to their underlying factor indices. We also believe that larger companies which follow stricter ESG principles and practices, have built up better resistance to systematic market shocks, their financials are more predictable than others and they earn a higher equity premium and hence have a lower cost of capital.

Though the factor-based model shows that ESG overlay provides higher alpha in the case of all the underlying factor indices, in a market model set-up it does not hold true across all the indices. Quality index provides highest return followed by Quality ESG Target index, Multi-Factor ESG Target index, Minimum Volatility ESG Target index, Minimum Volatility index and Multi-Factor index, while both Value ESG Target and Value indices provide lower than market returns. Both Minimum Volatility and Minimum Volatily ESG target indices have minimum response to market volatility risks, while the Value and Value ESG Target indices are the worst affected by market conditions. The Quality ESG Target index is more responsive to market downside risk as compared to its underlying counterpart, though both the indices track the market closely, albeit with some positive bias. Both the Multi-Factor and Multi-Factor ESG Target indices follow the market closely, though the latter is less volatile, more responsive to upward 
movements and less responsive to downslides as compared to its underlying conterpart. We noticed that except for Quality, an ESG overlay provides better results as compared to their underlying factor indices.

Quality is the most important factor in the market that generates excess return compared to the benchmark, captures the lowest downside risk, captures the higest rewards from volatility, is a better revival indicator post market downturns and can provide higher average compounded annual return against maximum drawdowns, over a period. The Multi-Factor ESG Target index has a slightly better performance ratio as compared to its underlying counterpart, though the Minimum Volatility ESG Target and Minimum Volatility indices are better in terms of their ability to revive post market downturns and provide better average compounded annual return against maximum drawdowns, over a period. This also reaffirms that though the Minimum Volatility and Minimum Volatility ESG Target indices may provide lowest alphas in a multi-factor model regression, they are indeed better in terms of downside risk protection. Both Value ESG Target and Value indices have a negative information ratio, as they are more prone to market risk, overeact to market downslides and are slow in their response to market revivals.

We observed that both the alpha and beta values of these indices change significantly over time as the factor betas are influenced to a varying degree, depending upon the market conditions. Deeper analysis shows that both Quality and Quality ESG indices are highly responsive to the RMW, i.e., the underlying stocks respond faster to a market revival as they are profitable and to some extent, they also have slightly lower volatility as compared to the market. Both Minimum Volatility and Minimum Volatility ESG indices protect downside risk, as they are also highly responsive to a revival of downturn and count positively on the CMA factor.

In major market downturns such as the global financial crisis, the Minimum Volatility ESG Target and Minimum Volatility indices show strong resistance to downside risk, followed by both the Quality and Quality ESG Target indices, while both the Multi-Factor and Multi-Factor ESG Target indices closely followed the market; both, Value and Value ESG Target indices are highly prone to market downturns. During the second major market drawdown due to the onset of the COVID-19 pandemic outbreak, Quality and Minimum ESG Target and their underlying factor indices showed better resistance, while both the Value and Value ESG Target indices were the worst impacted. Typically, during this phase all the ESG indices showed better resistance to market downturns, except for Quality. When we consider the upsides of market movements, ESG overlay has some additional positive impact compared to their underlying factor indices.

\section{Declarations}

Conflict of interest On behalf of all authors, the corresponding author states that there is no conflict of interest. 


\section{References}

Acharya, V.V., and L.H. Pedersen. 2005. Asset pricing with liquidity risk. Journal of Financial Economics 77 (2005): 375-410.

Altman, E.I. 1968. Financial ratios, discriminant analysis and the prediction of corporate bankruptcy. Journal of Finance 23 (4): 589-609.

Ang, A., R.J. Hodrick, Y. Xing, and X. Zhang. 2006. the cross-section of volatility and expected returns. Journal of Finance 61: 259-299.

Asness, Clifford S., Andrea Frazzini, and Lasse Heje Pedersen. Quality minus junk. Review of Accounting Studies 24, 34-112 (2019). https://doi.org/10.2139/ssrn.2312432.

Barberis, N., and M. Huang. 2008. Stocks as lotteries: The implications of probability weighting for security prices. American Economic Review 98: 2066-2100.

Black, Fisher, Michael C. Jensen, and Myron Scholes. 1972. The capital asset pricing model: Some empirical Tests. In Studies in the theory of capital markets, ed. Michael C. Jensen, 79-121. New York: Praeger.

Campbell, John Y., J. Hilscher, and J. Szilagyi. 2008. In search of distress risk. The Journal of Finance, LXII I (6): 2899-2939.

Campbell, John Y., and Robert J. Shiller. 1988. Stock prices, earnings and expected dividends. Journal of Finance XLII I (3): 661-676.

Clark, Casey, Tensie Whelan, and Ulrich Atz. 2021. ESG and financial performance: Uncovering the relationship by aggregating evidence from 1,000 plus studies published between 2015-2020, NYU Stern Center for Sustainable Business and Rockefeller Asset Management. https://rcm. rockco.com/insights_item/esg-and-financial-performance/ and https://www.stern.nyu.edu/sites/ default/files/assets/documents/NYU-RAM_ESG-Paper_2021\%20Rev_0.pdf.

Clark, Gordon L., Andreas Feiner, and Michael Viehs. 2015. From the stockholder to the stakeholder: How sustainability can drive financial outperformance. Smith School of Enterprise and the Environment, European Centre for Corporate Engagement (ECCE) and Arabesque Asset Management. https://doi.org/10.2139/ssrn.2508281.

Asness, Clifford S., Andrea Frazzini, and Lasse H. Pedersen. 2012. Leverage aversion and risk parity. Financial Analysts Journal 68 (1): 47-59.

Cohen, R., C. Polk, and T. Vuolteenaho. 2009. The price is (almost) right. Journal of Finance 64 (6): 2739-2782.

Dunn, J., S. Fitzgibbons, and L. Pomorski. 2016. Assessing risk through environmental, social and governance exposures. AQR Research Paper. www.aqr.com.

Eccles, R., G. Serafeim, and M. Krzus. 2011. Market interest in nonfinancial information. Journal of Applied Corporate Finance 23 (4): 113-127.

El Ghoul, S., O. Guedhami, C. Kwok, and R. Mishra. 2011. Does corporate social responsibility affect the cost of capital? Journal of Banking and Finance 35 (9): 2388-2406.

Fama, Eugene F., and Kenneth R. French. 2008. Average returns, B/M, and share issues. The Journal of Finance 63 (6): 2971-2995.

Fama, Eugene F., and Kenneth R. French. 2015. A Five-factor Asset Pricing Model. Journal of Financial Economics 116: 1-22.

For detailed information on the construction of these indices, kindly refer to Index Construction Methodology of MSCI.

Frazzini, Andrea, and Lasse Heje Pedersen. 2014. Betting against Beta. Journal of Financial Economics 111: 1-25.

Friede, Gunnar, Timo Busch, and Alexander Bassen. 2015. ESG and financial performance: Aggregated evidence from more than 2000 empirical studies. Journal of Sustainable Finance \& Investment 5 (4): 210-233. https://doi.org/10.1080/20430795.2015.1118917.

Fulton, Mark, Bruce Kahn, and Camilla Sharples. 2012. Sustainable investing: Establishing long-term value and performance. SSRN. https://doi.org/10.2139/ssrn.2222740.

George, T.J., and C. Hwang. 2010. A resolution of the distress risk and leverage puzzles in the cross section of stock returns. Journal of Financial Economics 96 (1): 56-79.

Godfrey, P., C. Merrill, and J. Hansen. 2009. The relationship between corporate social responsibility and shareholder value: An empirical test of the risk management hypothesis. Strategic Management Journal 30: 425-445. 
Gregory, A., R. Tharyan, and J. Whittaker. 2014. Corporate social responsibility and firm value: Disaggregating the effects on cash flow, risk and growth. Journal of Business Ethics 124 (4): 633-657.

Harvey, C.R., C. Lundblad, and G. Bekaert. 2007. Liquidity and expected returns: Lessons from emerging markets. The Review of Financial Studies 20 (5): 1784-1831.

Hicks, J.R. 1939. Value and capital, p. 126. New York: Oxford University Press. Applies to firm specific risk rather than a portfolio.

Hoepner, A., M. Rezec, and S. Siegl. 2013. Does pension funds' fiduciary duty prohibit the integration of environmental responsibility criteria in investment processes? A realistic prudent investment test. Working Paper in Responsible Banking \& Finance, Number 13-010, School of Management, University of St. Andrews.

Hong, H., and M. Kacpercyk. 2009. The price of sin: The effects of social norms on markets. Journal of Financial Economics 93 (1): 15-36.

http://ec.europa.eu/enterprise/policies/sustainable-business/index_en.htm.

http://reports.weforum.org/impact-investing-charting-the-course/3-the-economic-viability/3-1-lessonsfrom-esg-integration/.

http://www.ifc.org/wps/wcm/connect/Topics_Ext_Content/IFC_External_Corporate_Site/Sustainability+ and+Disclosure/ $>$ Environmental-Social-Governance.

http://www.undp.org/content/undp/en/home/sdgoverview/mdg_goals.html.

http://www.unpri.org/about-pri/the-six-principles/.

https://www.cfainstitute.org/learning/future/pages/esg.aspx.

https://www.oecd.org/daf/ca/SecondMeetingLatinAmericaSOECAFWhitePaper.pdf, p. 7.

Jensen, Michael C. 1986. Agency costs of free cash flow, corporate finance, and takeovers. The American Economic Review 76 (2): 323-329.

Jiao, W. 2009. Stakeholder welfare and firm value. Journal of Banking \& Finance 34 (10): 2549-2561.

Jo, H., and H. Na. 2012. Does CSR reduce firm risk? Evidence from controversial industry sectors. Journal of Business Ethics 110: 441-456.

Khan, Mozaffar, George Serafeim, and Aaron Yoon. 2016. Corporate sustainability: First evidence on materiality. The Accounting Review 91 (6): 1697-1724. https://doi.org/10.2139/ssrn.2575912.

Lintner, John. 1965. The valuation of risk assets and the selection of risky investments in stock portfolios and capital budgets. Review of Economics and Statistics. 47 (1): 13-37.

McDonough, William, and Michael Braungart. 2002. Design for the triple top line: New tools for sustainable commerce. Corporate Environmental Strategy 9 (3): 251. Triple top line (abbreviated as TTL or 3TL), first mentioned by McDonough and Braungart (2002), offsets in the principles of the Triple bottom line accounting framework coined by John Elkington in 1994.

Merton, Robert C. 1973. An intertemporal capital asset pricing model. Econometrica 41: 867-887.

Mitton, T., and K. Vorkink. 2007. Equilibrium, underdiversification and the preference for skewness. Review of Financial Studies 20: 1255-1288.

Mohanty, Subhransu S. 2018. Does one model fit all in global equity markets? Some insight into market factor based strategies in enhancing alpha. International Journal of Finance and Economics. https:// doi.org/10.1002/ijfe.1710.

Oikonomou, I., C. Brooks, and S. Pavelin. 2012. The impact of corporate social performance on financial risk and utility: A longitudinal analysis. Financial Management 41: 483-515.

Ohlson, J.A. 1980. Financial ratios and the probabilistic prediction of bankruptcy. Journal of Accounting Research 18 (1): 109-131.

Pedersen, Lasse, Shaun Fitzgibbons, and Lukasz Pomorski. 2020. Responsible investing: The ESG-efficient frontier. Journal of Financial Economics. https://doi.org/10.1016/j.jfineco.2020.11.001.

Penman, S., S. Richardson, and I. Tuna. 2007. The book-to-price effect in stock returns: Accounting for leverage. Journal of Accounting Research 45 (2): 427-467.

Renneboog, L., J.T. Horst, and C. Zhang. 2008. Socially responsible investments: Institutional aspects, performance, and investor behavior. Journal of Banking \& Finance 32 (9): 1723-1742.

Ross, S.A. 1976. The arbitrage theory of capital asset pricing. Journal of Economic Theory 13 (3): 341-360.

Ruefli, T., J. Collins, and J. Lacugna. 1999. Risk measures in strategic management research: Auld Lang Syne? Strategic Management Journal 20 (2): 167-194.

Sharpe, William F. 1964. Capital asset prices: A theory of market equilibrium under conditions of risk. The Journal of Finance 19 (3): 425-442.

UN PRI. 2010. Universal ownership: Why environmental externalities matter to institutional investors, PRI and Trucost, October 2010. 
Vuolteenaho, T. 2002. What drives firm-level stock returns? The Journal of Finance 57 (1): 233-264.

Zhang, Y. 2006. Individual skewness and the cross-section of average stock returns. Working Paper, Yale University.

Publisher's Note Springer Nature remains neutral with regard to jurisdictional claims in published maps and institutional affiliations.

Subhransu S. Mohanty is the President Emeritus, SMART International Holdings, Inc., Wilmington, DE, USA, a global investment consulting firm focused on risk-adjusted return based investment strategies. He most recently worked as Director and Professor of Finance at St. Francis Institute of Management \& Research, Mumbai and is currently associated with Professor Mike Ivanof, School of Business, University of the Fraser Valley, BC, Canada on a collaborative research project on 'Sustainable Investing'. He has managed global multi-asset-class investment portfolios and has over 27 years of industry and teaching experience mainly in the investment and capital markets areas. He has about 26 published papers, 29 monographs and 39 newspaper articles to his credit. He has his Masters and Ph.D. from Banaras Hindu University and a specialized MBA in Global Asset and Wealth Management from Simon Fraser University, Canada.

Odette Mohanty is currently working as Executive Manager-Investments, Treasury \& International Banking, Bank Dhofar SAOG, Muscat, Oman. She has extensive work experience of nearly 25 years in the investment industry and she specializes in investment management, portfolio construction techniques, commodities investing, renewable energy investments, life sciences and healthcare, climate risk analysis for investments as well as ESG integration strategies. She is a Chartered Investment Manager and a Fellow of the Canadian Securities Institute.

Mike Ivanof is currently working as an Associate Professor with the School of Business, University of the Fraser Valley, Abbotsford, Canada. Dr Ivanof is a Global citizen with a career that spans more than a dozen countries on four continents. His career combines substantive industry experience in finance and business development, and over a decade in academia. His academic research interests revolve mainly around Corporate Governance and Corporate Social Responsibility. He has a Ph.D. in Business Administration, MBA, BSc., CPA and CGA. 